\title{
Expression of the VEGF and angiopoietin genes in endometrial atypical hyperplasia and endometrial cancer
}

\author{
CM Holland ${ }^{*, 1,2}, K^{\text {Day }}{ }^{2}$, A Evans' and SK Smith ${ }^{1,2}$ \\ 'Department of Pathology, University of Cambridge, Tennis Court Road, Cambridge CBI IQP, UK; ${ }^{2}$ Department of Obstetrics and Gynaecology, \\ University of Cambridge, The Rosie Hospital, Robinson Way, Cambridge CB2 2SW, UK
}

\begin{abstract}
Angiogenesis is critical for the growth and metastasis of endometrial cancer and is therefore an important therapeutic target. Vascular endothelial growth factor-A (VEGF-A) is a key molecule in angiogenesis, but the identification of related molecules and the angiopoietins suggests a more complex picture. We investigated the presence of transcripts for VEGF-A, VEGF-B, VEGF-C, VEGF-D, Angiopoietin-I and Angiopoietin-2 in benign endometrium, atypical complex hyperplasia $(\mathrm{ACH})$ and endometrioid endometrial carcinoma using in situ hybridisation. We confirmed the presence of VEGF-A mRNA in the epithelial cells of cancers examined (I 3 out of I3), but not in benign endometrium or ACH. We also demonstrate, using quantitative polymerase chain reaction, that levels of VEGF-B mRNA are significantly lower in endometrial cancer than benign endometrium. We conclude that loss of VEGF-B may contribute to the development of endometrial carcinoma by modulating availability of receptors for VEGF-A.

British Journal of Cancer (2003) 89, 89I-898. doi:I0.1038/sj.bjc.660II94 www.bjcancer.com

(c) 2003 Cancer Research UK
\end{abstract}

Keywords: VEGF-B; angiopoietins; endometrial cancer; endometrial hyperplasia; in situ hybridisation

Angiogenesis is a critical event in the growth and spread of tumours (Folkman, 1990). The vascular endothelial growth factor family (VEGFs) and the angiopoietins are key factors in this process (Fong et al, 1995; Shalaby et al, 1995; Ferrara et al, 1996; Maisonpierre et al, 1997; Thurston et al, 1999). Vascular endothelial growth factor-A is a dimeric glycoprotein existing as four main isoforms by alternative splicing from a single gene. The coding regions of the VEGF gene comprise eight exons. The first four are conserved but alternative splicing of the last four gives rise to mRNAs of 121,145, 165, 189 and 206 amino acids, respectively $\left(\mathrm{VEGF}_{121}, \mathrm{VEGF}_{145}, \mathrm{VEGF}_{165}, \mathrm{VEGF}_{189}, \mathrm{VEGF}_{206}\right.$ ) (Houck et al, 1991; Tischer et al, 1991; Charnock-Jones et al, 1993). The VEGF-A isoforms bind the tyrosine kinase receptors VEGFR-1 (flt-1) and VEGFR-2 (KDR/flk-1) to promote endothelial cell proliferation, migration and increased vascular permeability. Elevated levels of VEGF-A are found in many tumours including cancers of the endometrium (Doldi et al, 1996; Fujimoto et al, 1998) and ovarian epithelium (Olson et al, 1994; Boocock et al, 1995; Abu-Jawdeh et al, 1996). When VEGF-A signalling is blocked with VEGFneutralising antibodies (Olson et al, 1996) or dominant-negative receptors (Millauer et al, 1994), tumour angiogenesis and growth are impaired.

However, the family of VEGF genes has expanded with the discovery of other VEGFs, for example, VEGF-B (Olofsson et al,

\footnotetext{
*Correspondence: Dr CM Holland, Box 223, Department of Obstetrics and Gynaecology, University of Cambridge, The Rosie Hospital, Robinson Way, Cambridge CB2 2SW, UK;

E-mail: cath.holland@obgyn.cam.ac.uk

Received 2I November 2002; revised 9 June 2003; accepted 24 June 2003
}

1996a), VEGF-C (Joukov et al, 1996) and VEGF-D (Achen et al, 1998), which share significant sequence homology with VEGF-A. VEGF-B exists as two splice variants, a heparin binding isoform of 167 amino acids (VEGF- $B_{167}$ ) and a secreted isoform of 186 amino acids (VEGF-B ${ }_{186}$ ) (Olofsson et al, 1996b). Whereas VEGF-A binds to both the VEGFR-1 and VEGFR-2 receptors, VEGF-B binds only to the VEGFR-1 receptor (flt-1) (Olofsson et al, 1998). Vascular endothelial growth factor-B forms homodimers and can heterodimerise with VEGF-A (Olofsson et al, 1996a) to promote endothelial cell proliferation in vitro (Olofsson et al, 1996a).

Both VEGF-C and VEGF-D are ligands for VEGFR-2 (KDR) and the third VEGF receptor VEGFR-3 (flt-4) (Joukov et al, 1996; Achen et al, 1998). VEGFR-3 is expressed by adult lymphatic endothelial cells but not by adult vascular endothelium. There is a strong association between lymphovascular density and VEGF-C expression in human malignant mesothelioma, suggesting this pathway as an important therapeutic target (Ohta et al, 1999).

A second family of growth factors, the angiopoietins, are ligands for the tyrosine kinase receptor Tie-2 (Davis et al, 1996; Maisonpierre et al, 1997). The two ligands share $60 \%$ sequence homology and bind with equal affinity to Tie-2. Angiopoietin-1 (Ang-1) maintains pericyte/endothelial cell interactions (Hanahan, 1997; Thurston et al, 1999) while Angiopoietin-2 (Ang-2) is a functional antagonist of Ang-1 and leads to marked vessel regression in tumours in the absence of VEGF-A (Holash et al, 1999). Compared to Ang-1, which is widely expressed in adult tissues, Ang-2 is selectively expressed at sites of active angiogenesis, for example, the corpus luteum of the ovary (Goede et al, 1998) and endometrium (Li et al, 2001).

Angiogenesis is an important feature of endometrial cancer as microvessel density is an independent prognostic indicator of both progression and overall survival (Kaku et al, 1997). Furthermore, there is a progressive increase in microvessel density from benign 
endometrium through the cancer precursor, atypical complex hyperplasia (ACH) to invasive disease (Abulafia et al, 1995).

While VEGF-A mRNA and protein are present in endometrial cancer (Doldi et al, 1996; Guidi et al, 1996; Fujimoto et al, 1998), its expression in $\mathrm{ACH}$ is unknown. Vascular endothelial growth factor-C (Hirai et al, 2001) and VEGF-D (Yokoyama et al, 2003) have both been correlated with a poor prognosis in endometrial cancer, but the expression of VEGF-B has not been described. In order to further investigate a possible role for other angiogenic factors in endometrial cancer, we investigated the presence of transcripts for VEGF-A, VEGF-B, VEGF-C, VEGF-D, Ang-1 and Ang-2 in benign postmenopausal endometrium, $\mathrm{ACH}$ and endometrioid endometrial carcinoma by in situ hybridisation and used quantitative polymerase chain reaction (PCR) to determine the levels of VEGF-B and Ang-2 mRNA in benign and malignant endometrium.

\section{MATERIALS AND METHODS}

\section{Patients}

A total of 13 carcinoma specimens were examined using in situ hybridisation. All were endometrioid-type carcinomas. Five benign postmenopausal endometrial specimens and five complex atypical hyperplasias were also examined for comparison. The age range of the patients was 51-87 years (median 57 years). Histopathological findings and clinical data are shown in Table 1. Presence or absence of lymphovascular space involvement is indicated, where reported, in the table. The survival status for each patient was noted at the time of preparation of this manuscript. Ethical committee approval was obtained from the committee of Addenbrookes Hospital NHS Trust.

\section{Tissue samples}

In situ hybridisation and immunohistochemistry were performed on formalin-fixed, paraffin-embedded endometrial tissue. Tissue used for reverse transcription-PCR (RT-PCR) and quantitative PCR was snap-frozen from endometrium removed during endometrial curettage or total hysterectomy, after examination by a histopathologist.

\section{Production of radiolabelled riboprobes for in situ hybridisation}

Antisense and sense (control) RNA probes were generated against VEGF-A, VEGF-B, VEGF-C, VEGF-D, angiopoietin-1 and angiopoietin-2 (Sowter et al, 1997). For VEGF-A, probes were designed to span the first four exons thus detecting the four commonly occurring isoforms. The sequences were amplified in pCRscript SK (Stratagene Ltd., Cambridge, UK) and pBluescript II KS vectors (Stratagene Ltd., Cambridge, UK). Radioactive, single-stranded probes incorporating ${ }^{33} \mathrm{P}$-UTP (Amersham International plc, Little Chalfont, Buckinghamshire, UK) were carried out with $1 \mu \mathrm{g}$ plasmid template using the Ambion MAXIscript transcription kit (Ambion Inc., Austin, TX, USA) before phenol extraction and ethanol precipitation.

\section{Identification of mRNA encoding VEGF-A, VEGF-B, VEGF-C, VEGF-D, angiopoietin-1 and angiopoietin-2 by in situ hybridisation}

Tissue sections $(6 \mu \mathrm{m})$ were cut onto slides coated with 3aminopropyltriethoxy-silane (Sigma Chemical, Poole, Dorset, UK). The hybridisation procedure was performed as described by Clark et al (1996). The riboprobe was incubated with the tissue sections for $18 \mathrm{~h}$ at $55^{\circ} \mathrm{C}$. The sections were washed and treated with RNAse A (Sigma Chemicals, St Louis, USA), before being coated with autoradiographic emulsion (Amersham Pharmacia Biotech UK Ltd, Aylesbury, UK) and exposed for 21 days at $4{ }^{\circ} \mathrm{C}$. Sections were developed with photographic developer (Kodak D19) and counterstained with Mayer's haemalum (BDH Chemicals, Lutterworth, UK) before viewing.

\section{Immunohistochemistry for cytokeratin and CD-68}

Immunohistochemistry was performed on serial sections to identify the cell types expressing the transcripts. Mouse antibodies to human cytokeratin (clone MNF116; Dako, Ltd., High Wycombe,

Table I Clinical and histopathological details for patient samples used in the study

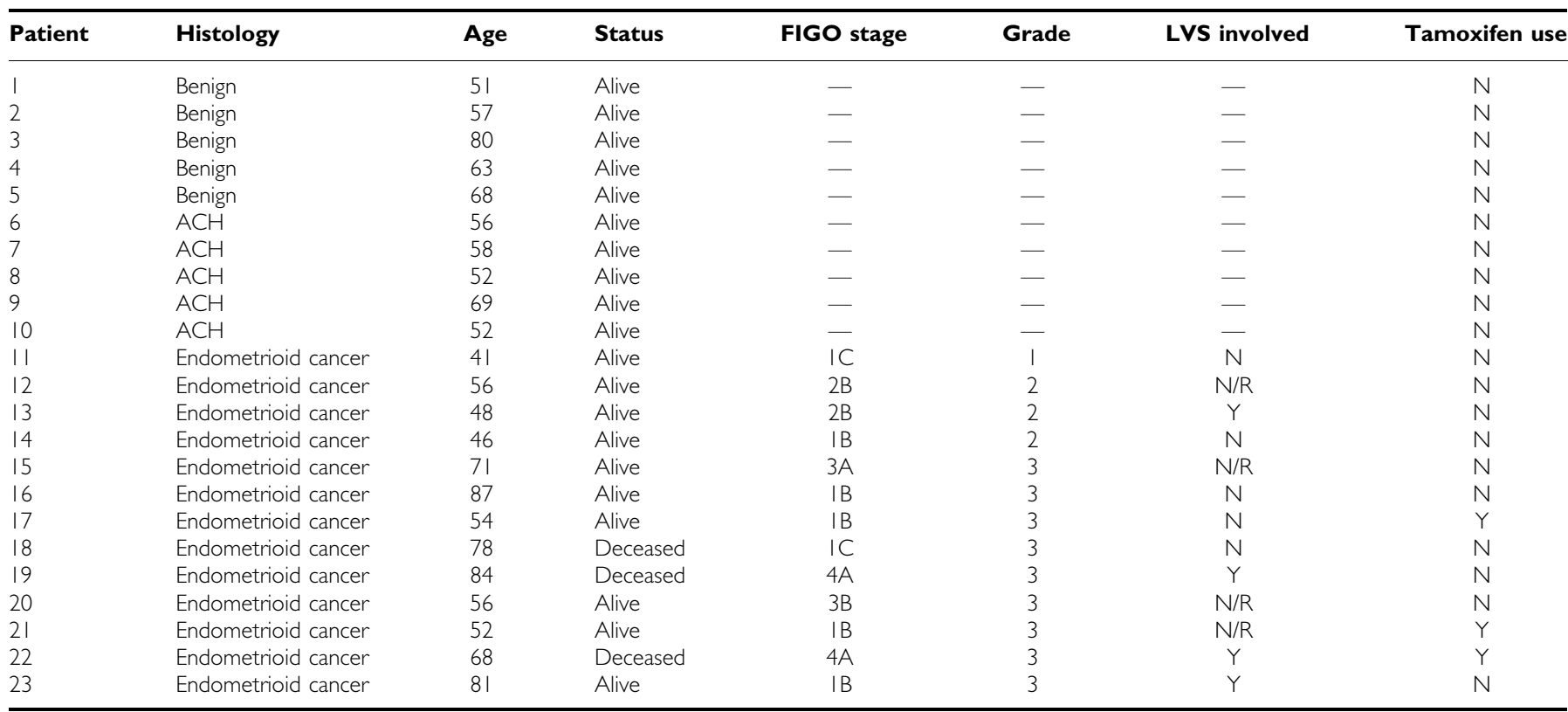

$\mathrm{ACH}=$ atypical complex hyperplasia; $\mathrm{LVS}=$ lymphovascular space involvement $\mathrm{N} / \mathrm{R}=$ not reported $\mathrm{N}=$ never, $\mathrm{Y}=$ yes. 
Buckinghamshire, UK) and human CD68, a macrophage marker, (clone PG-1; Dako, Ltd.) were used as described previously (Clark et al, 1996). Mouse IgG (Dako, Ltd.) incubated with serial sections provided negative controls.

\section{Reverse transcription - PCR}

RNA from benign postmenopausal endometrium, $\mathrm{ACH}$ and endometrioid endometrial carcinoma was analysed by RT-PCR to determine whether mRNA for VEGF-C was present (Figure 1). Total RNA was extracted from snap-frozen tissue using acid phenol purification (Chomczynski and Sacchi, 1987). Samples for PCR were unrelated to those used for in situ hybridisation. RNA was annealed with oligo-dT primers (Pharmacia Biotech LTD., St Albans, UK) and cDNA was synthesised using reverse transcriptase (HT Biotechnology LTD., Cambridge, UK). Polymerase chain reaction for VEGF-C was performed using the upstream primer $5^{\prime}$ TGCCGATGCATGTCTAAACT- $3^{\prime}$, and the downstream reverse complement primer 5'-TGAACAGGTCTCTTCATCCAGC-3' for 40 cycles $\left(15 \mathrm{~s}\right.$ at $95^{\circ} \mathrm{C}$ and $60 \mathrm{~s}$ at $\left.60^{\circ} \mathrm{C}\right)$.

\section{Quantitative PCR}

RNA was extracted and purified and cDNA was prepared as above. Quantitative, real-time PCR was performed in triplicate using the ABI PRISM 7700 Sequence Detector (Applied Biosystems, Warrington, UK) according to the manufacturer's instructions and the resultant data were averaged. Non-template controls were included in each experiment. Specific oligonucleotide primers and probes were designed for VEGF-B using Primer Express ${ }^{\circledR} 1.5$ software (Applied Biosystems, Warrington, UK). Specific primers and probe for Ang-2 were a gift from Mrs K Day of The Reproductive Molecular Research Group at the University of Cambridge Department of Obstetrics and Gynaecology. Details for VEGF-B primers and probe are shown below.

\section{Forward primer, $5^{\prime}$ - AGCACCAAGTCCGGATG $-3^{\prime}$}

Reverse primer, $5^{\prime}$ - GTCTGGCTTCACAGCACTG - $3^{\prime}$

Probe, $5^{\prime}$-6FAM - AGATCCTCATGATCCGGTACCCGT - $3^{\prime}$

A $1 \mu \mathrm{l}$ volume of each cDNA was amplified using PCR Master Mix (Applied Biosystems, Warrington, UK) under the following PCR conditions: $50^{\circ} \mathrm{C}$ for $2 \mathrm{~min}, 95^{\circ} \mathrm{C}$ for $10 \mathrm{~min}$, followed by 40 cycles of $95^{\circ} \mathrm{C}$ for $15 \mathrm{~s}$ and $60^{\circ} \mathrm{C}$ for $1 \mathrm{~min}$. $\beta$-Actin and $18 \mathrm{~s}$ RNA were used as endogenous control sequences for VEGF-B and Angiopoietin-2, respectively. Preliminary experiments confirmed that the endogenous control sequences were amplified at the same rate as the target sequences (data not shown). The threshold cycle $\left(C_{\mathrm{T}}\right)$ was determined for each sample. $C_{\mathrm{T}}$ value is the cycle number at which the level of reporter fluorescence rises above a preset threshold level. Normalisation was achieved by subtracting the mean $C_{\mathrm{T}}$ value for each endogenous control triplicate from the mean $C_{\mathrm{T}}$ value for each target gene triplicate. Target gene abundance was calculated for each tissue type.

I $r$ C A B CDEFGH I JKLMNO PQR S TU V W

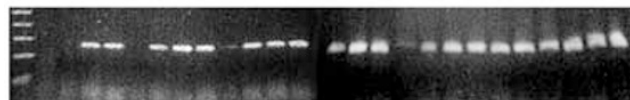

$246 \mathrm{bp}$

Figure I Reverse transcription PCR analysis of VEGF-C in samples of benign endometrium $(A-G), A C H(H-J)$ and endometrioid endometrial carcinoma. Well differentiated carcinoma $(K-M)$, moderately differentiated carcinoma $(\mathrm{N}-\mathrm{S})$ and poorly differentiated carcinoma $(\mathrm{T}-\mathrm{W})$. Lane $r$ represents an RNA control in which the RT step was omitted and lane $c$ represents a negative control in which the cDNA was replaced by water. The size of the transcripts (shown on the right of the figure) was estimated by co-electrophoresis of a I kb ladder (lane I).

\section{Statistical analyses}

The presence or absence of specific in situ hybridisation for each transcript was compared across the different histological categories using the two-tailed Fisher's exact probability test. This was computed using the $R$ statistical computing programme (www.rproject.org). Statistical significance was accepted as $P<0.05$. For results of quantitative PCR, normalised log-transformed transcript levels were compared between groups using the unpaired Student's $t$-test (two-tailed).

\section{RESULTS}

\section{Expression of members of the VEGF family and angiopoietins by in situ hybridisation}

The presence of VEGF-A was detected in all cases of endometrioid endometrial cancer (Table 2 and Figure 2) and was increased near areas of necrosis. Hybridisation for VEGF-A was not seen in cases of $\mathrm{ACH}$ or in sections of benign postmenopausal endometrium.

In contrast, hybridisation of the VEGF-B riboprobe was seen in all the five cases of ACH (Table 2 and Figure 2). There was continued expression for VEGF-B in low-grade tumours that diminished as the grade of the tumour increased. Vascular endothelial growth factor-B mRNA was also present in epithelial and stromal compartments (Figure 2), although, unlike VEGF-A, there was no apparent increase in hybridisation near areas of necrosis.

Messenger RNA encoding VEGF-C was not detected in any of the tissues examined using in situ hybridisation (Table 2 and Figure 1). A specimen of human lymphoma was used as a positive control and demonstrated specific hybridisation (Figure 2). However, PCR amplification of VEGF-C cDNA was seen in all the samples of endometrial cancer (13 out of 13) and ACH (three out of three) examined (Figure 1), in addition to six out of 7 benign postmenopausal endometria. These findings confirm the presence of VEGF-C in benign, premalignant and malignant endometrium (Hirai et al, 2001), although at levels beneath the detection threshold for in situ hybridisation.

Messenger RNA encoding VEGF-D was present in three of the five $\mathrm{ACH}$ specimens and in six of the 13 carcinomas (one moderately differentiated tumour and five poorly differentiated tumours). The distribution of silver grains did not correspond with epithelial tumour cells but did co-localise with tumour-associated macrophages (CD-68 positive cells) in serial sections (Figure 3).

Hybridisation for Ang-1 mRNA was seen in only one benign and one ACH specimen. Similarly, mRNA encoding Ang-2 was seen in no benign tissues and in only one of the five hyperplastic samples. In contrast, while hybridisation was absent in well/moderately differentiated cancers, hybridisation for Ang-2 mRNA was clearly demonstrated in four out of nine of the poorly differentiated tumours examined. Hybridisation was most marked in macrophage-rich regions of these tumours and was seen to correspond with tumour-associated macrophages (CD-68) upon immunostaining of serial sections (Figure 3 ). In all of the experiments described, there was no specific hybridisation when the sense probes were used on adjacent sections.

\section{Transcript abundance of VEGF-B and Ang-2 in benign endometrium and endometrial carcinoma assessed by quantitative PCR}

Real-time, quantitative PCR was carried out using cDNA generated from benign postmenopausal endometria and endometrioid-type endometrial adenocarcinoma. The abundance of VEGF-B transcript was greater in benign endometrium $(n=7)$ than in atypical hyperplasia $(n=3)(P=0.13)$ and endometrial cancer $(n=17)$ $(P=0.04)$ (Figure 4A). Conversely, cDNA encoding Ang-2 was 

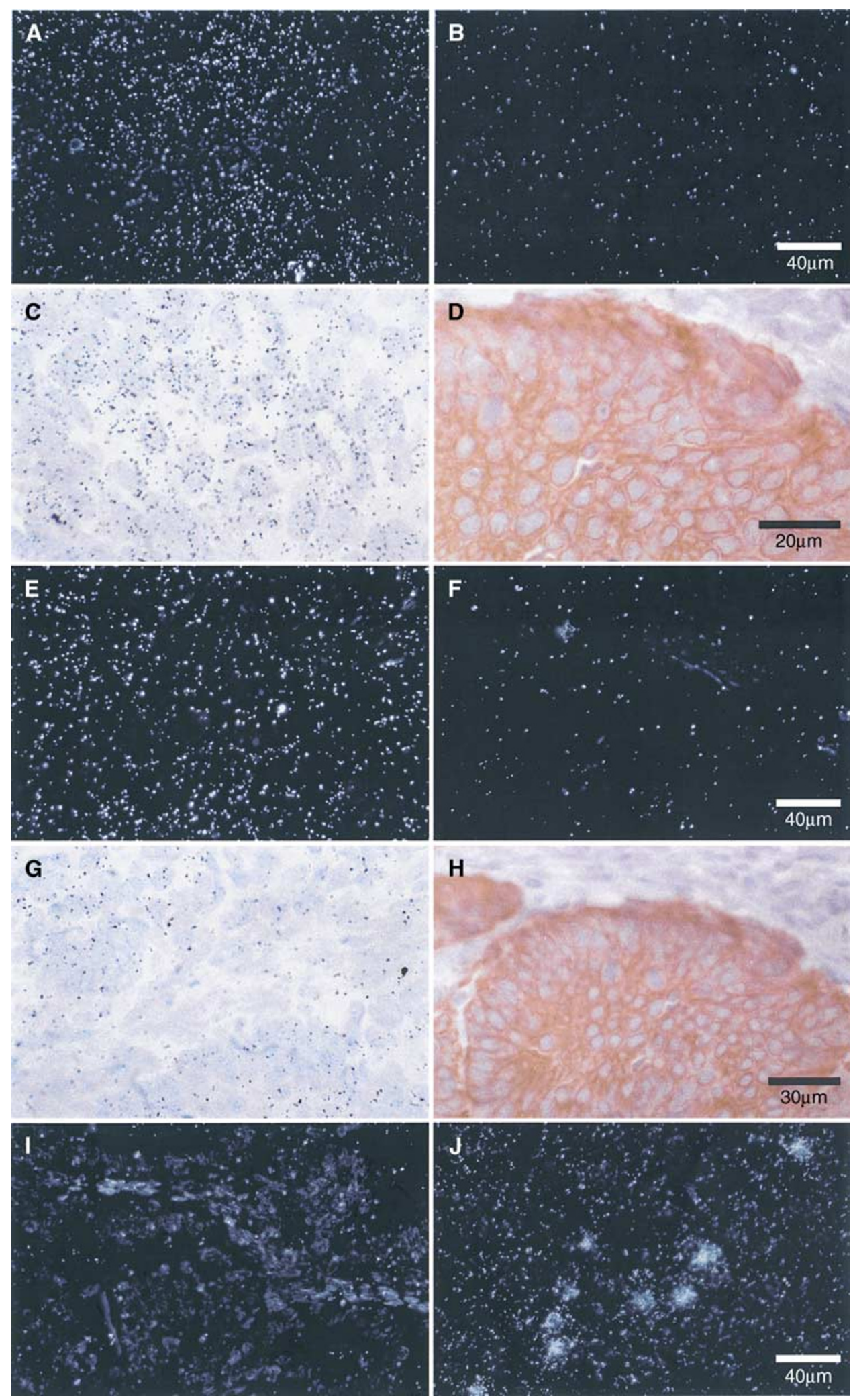

Figure 2 Expression of mRNA encoding VEGF-related factors in the epithelial cells of endometrioid endometrial carcinoma and ACH. In situ hybridisation with VEGF-A antisense probe in a moderately differentiated (FIGO grade 2) carcinoma shown under dark-field (A) and light-field (C) conditions shows hybridisation in epithelial carcinoma cells. There is no specific hybridisation when a sense probe (negative control) is used (B). The scale bar in (B) applies to (A), $(\mathbf{B}),(\mathbf{E}),(\mathbf{F}),(\mathbf{I})$ and $(\mathbf{J})$. Immunostaining of a serial section with anti-human cytokeratin confirms the epithelial localisation of silver grains (D) (scale bar applies to $\mathrm{ACH}(\mathbf{C})$ and $(\mathbf{D})$. In situ hybridisation with VEGF-B antisense probe in $\mathrm{ACH}$ shown under dark-field $(\mathbf{E})$ and light-field (G) conditions shows diffuse hybridisation in epithelial and stromal cells. There is no specific hybridisation when a sense probe (negative control) is used (F). Immunostaining with anti-human cytokeratin $(\mathbf{H})$ identifies the epithelial and stromal cells $(\mathbf{H})$ (scale bar applies to $(\mathbf{G})$ and $(\mathbf{H})$. In situ hybridisation with VEGF-C antisense probe in a poorly differentiated (FIGO grade 3) carcinoma shown under dark-field conditions (I) shows no specific hybridisation when compared with a human B-cell lymphoma (J). 
Table 2 Expression of VEGF-A, VEGF-B, VEGF-C, VEGF-D, Ang-I and Ang-2 detected by in situ hybridisation in sections of endometrium

\begin{tabular}{lccccccc}
\hline Endometrial histology & $\boldsymbol{n}$ & VEGF-A & VEGF-B & VEGF-C & VEGF-D & ANG-I & ANG-2 \\
\hline Benign & 5 & $0 / 5$ & $0 / 5$ & $0 / 5$ & $0 / 5$ & $1 / 5$ & $0 / 5$ \\
ACH & 5 & $1 / 5$ & $5 / 5 *$ & $0 / 5$ & $3 / 5$ & $1 / 5$ & $1 / 5$ \\
FIGO GI/2 carcinoma & 4 & $4 / 4 *$ & $3 / 4$ & $0 / 4$ & $1 / 4$ & $0 / 4$ & $0 / 4$ \\
FIGO G3 carcinoma & 9 & $9 / 9 *$ & $4 / 9$ & $0 / 9$ & $5 / 9$ & $0 / 9$ & $4 / 9$
\end{tabular}

$* P<0.05$
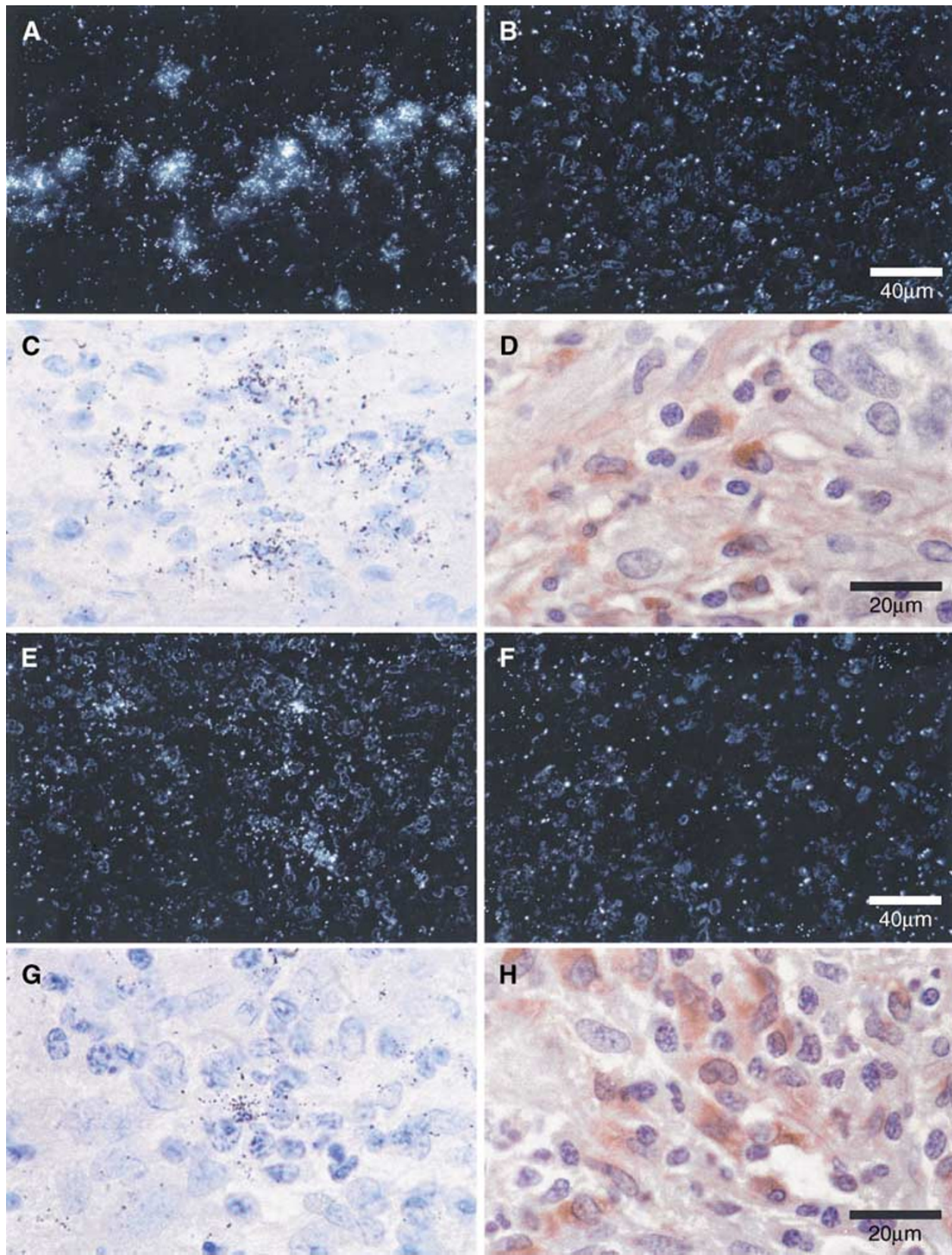

Figure 3 Expression of mRNA encoding VEGF-D and Ang-2 in macrophages infiltrating a poorly differentiated (FIGO grade 3) endometrioid endometrial carcinoma. In situ hybridisation with VEGF-D antisense probe shown under dark-field $(\mathbf{A})$ conditions and light-field conditions $(\mathbf{C})$. In situ hybridisation with VEGF-D sense (control) probe shows no specific hybridisation (B) (scale bar applies to $(\mathbf{A}),(\mathbf{B}),(\mathbf{E})$ and $(\mathbf{F})$ ). Immunostaining with anti-human CD68 in a serial section (D), localises the silver grains to tumour associated macrophages (TAMs) (scale bar applies to $(\mathbf{C}),(\mathbf{D}),(\mathbf{G})$ and $(\mathbf{H})$ ). In situ hybridisation with Ang-2 antisense probe shown under dark-field $(\mathbf{E})$ and light-field $(\mathbf{G})$ conditions. In situ hybridisation with Ang-2 sense (control) probe (F) shows no specific hybridisation. Anti-human cytokeratin staining $(\mathbf{H})$ localises the hybridisation to TAMs. 


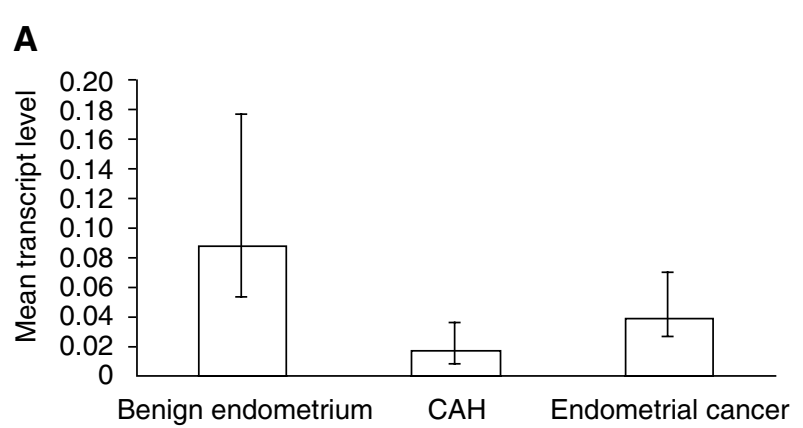

Histological diagnosis

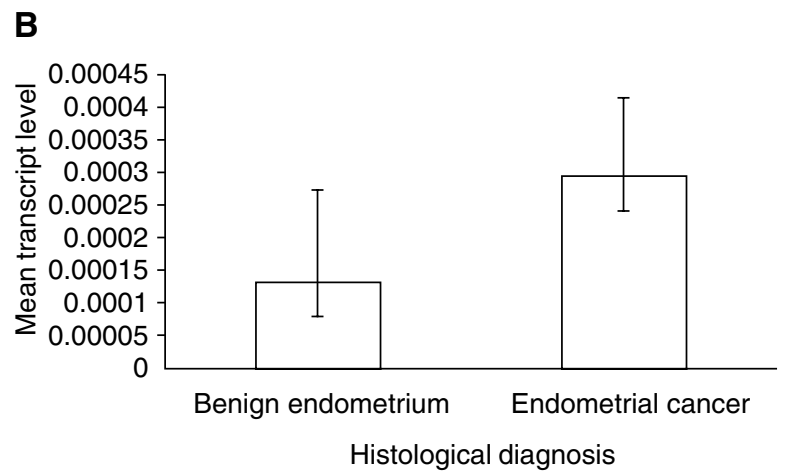

Figure 4 Quantitative PCR for gene transcripts in benign and malignant endometrium. Levels of gene transcript are shown normalised to an endogenous control sequence. Transcript levels are expressed as arbitrary units and represent the mean for each histological group. Experiments for each sample were performed in triplicate. (A) The level of mRNA encoding VEGF-B is generally higher in benign postmenopausal endometrium than in $\mathrm{CAH}(P=0.13)$ and endometrial cancer $(P=0.04)$. (B) mRNA encoding Ang-2 is generally present at higher levels in endometrial cancer than in benign postmenopausal endometrium.

more abundant in the cancer samples $(n=17)$ than in benign postmenopausal endometrium $(n=4)$ (Figure $4 \mathrm{~B}$ ), although this did not reach statistical significance $(P=0.49)$.

\section{DISCUSSION}

These findings confirm the expression of VEGF-A in endometrial cancer (Doldi et al, 1996; Guidi et al, 1996; Fujimoto et al, 1998; Fine et al, 2000), although in contrast to other published reports (Fujimoto et al, 1998; Fine et al, 2000), we did not demonstrate VEGF-A mRNA in benign specimens. This may be explained by the inclusion of both pre- and postmenopausal endometrium in other studies (Fujimoto et al, 1998). Messenger RNA for VEGF-A is abundant in premenopausal endometrium (Charnock-Jones et al, 1993). Our findings support those of Guidi et al (1996), who demonstrated little or no mRNA expression in benign atrophic endometrium. We demonstrated VEGF-A mRNA in only one out of 5 specimens of ACH compared with 13 out of 13 endometrioid cancers. These differences may be due to necrosis within the malignant tissue. Hypoxia, in necrotic areas of cancer, leads to the upregulation of transcription (Tischer et al, 1991) and increased stability of VEGF-A mRNA (Levy et al, 1996).

Messenger RNA and protein for the related growth factor VEGFB have previously been identified in other tumours including ovarian carcinoma (Sowter et al, 1997). We demonstrate, using quantitative PCR, that mRNA encoding VEGF-B is more abundant in benign postmenopausal endometrium than in endometrial adenocarcinoma. The results also suggest that there may be a relative loss of VEGF-B mRNA in ACH although this was not statistically significant and may reflect small sample numbers. We show, using in situ hybridisation, that where present, VEGF-B mRNA is expressed in both epithelium and stroma of $\mathrm{ACH}$ and some endometrial cancers. These findings contrast with the overexpression of VEGF-A seen in endometrial cancers (Doldi et al, 1996; Fujimoto et al, 1998). The distribution of VEGF-B in both epithelial and stromal compartments of atypical hyperplasia and some cancers is similar to that observed in ovarian cancer (Sowter et al, 1997), but in contrast to VEGF-A, hybridisation was not increased near areas of necrosis. Vascular endothelial growth factor-B is not upregulated by hypoxia (Silins et al, 1997) and this may explain the differences seen here.

The function of VEGF-B is not clear. Vascular endothelial growth factor-1 binds VEGFR-1 (flt-1) but not VEGFR-2 (KDR) (Olofsson et al, 1998), both of which are present in peritumoral endothelial cells of endometrial cancers (Guidi et al, 1996). Mouse 'knockout' experiments suggest that the VEGFR-1 plays a role in endothelial differentiation and/or interactions between the endothelium and extracellular matrix (Fong et al, 1995), whereas signalling through VEGFR-2 leads to endothelial cell proliferation and migration (Waltenberger et al, 1994). Vascular endothelial growth factor-B is therefore unlikely to promote endothelial cell proliferation or migration directly. However, VEGF-B signalling via VEGFR-1 may participate in the organisation of endothelialmatrix interactions as VEGF-B increases the expression of both uPA (urokinase-type plasminogen activator) and PAI-1 (plasminogen activator inhibitor-1) in endothelial cell cultures (Olofsson et al, 1996a). These play a role in matrix degradation and its inhibition, respectively.

Vascular endothelial growth factor-B could contribute to the maintenance of host-tumour responses. Vascular endothelial growth factor-A, produced by tumour cells, inhibits the functional maturation of immune dendritic cells from haemopoietic progenitor cells (Gabrilovich et al, 1996). This effect is mediated by binding to VEGFR-1 (Oyama et al, 1998). Therefore, loss of VEGF$\mathrm{B}$ may contribute to the escape of tumour cells from the host immune response by making more VEGFR-1 binding sites available for binding by VEGF-A. Vascular endothelial growth factor-B may thus act to suppress changes that favour the development of endometrial cancer.

We confirmed the presence of VEGF-C mRNA in endometrial carcinoma shown by Hirai et al (2001), but did not demonstrate this by in situ hybridisation. Intense hybridisation for VEGF-C mRNA is seen in endometrial natural killer cells (Li et al, 2001), hence the VEGF-C transcript may be present in non-tumour cells that were under-represented in our endometrial tissues.

Vascular endothelial growth factor-D binds to VEGFR-2 and VEGFR-3 (Achen et al, 1998), both of which are present in endometrial cancer (Guidi et al, 1996). In colon cancer, VEGFR-3 is associated with inflammatory infiltrates of TAMs (White et al, 2002) although VEGF-D has not been demonstrated in TAMs themselves. We have shown hybridisation for VEGF-D mRNA in $\mathrm{ACH}$ and both well differentiated and poorly differentiated tumours (Table 2), although not all cases in each group were positive. Recently, positive immunostaining for VEGF-D has been demonstrated in both epithelium and stroma of endometrial cancers with some cases of ACH also displaying immunopositivity (Yokoyama et al, 2003). In the latter study, 42 and $87 \%$ of stage I/II and stage III/IV tumours, respectively, showed significant immunostaining. These findings may reflect differences in the degree of inflammatory infiltration between individual tumours as well as increased expression of VEGF-D by the tumour cells. There is a tendency to higher TAM density in microvessel-rich tumours (Salvesen and Akslen, 1999), and our findings indicate that TAMs may assist in promoting angiogenesis in endometrioid endometrial carcinoma by the secretion of VEGF-D.

Angiopoietin-1 and Ang-2 are previously unreported in endometrial cancer. We demonstrated higher levels of Ang-2 
mRNA in endometrial cancers than benign endometrium, although this did not reach statistical significance. The latter may reflect the small numbers of samples in the benign group. Nonetheless, the distribution of mRNA for Ang-2, assessed by in situ hybridisation, was similar to that of VEGF-D in TAMs (Figure 3). Both Ang-2 and VEGF-D were only seen in association with CD68-positive cells, although CD68-positive cells, without hybridisation for either of these factors were also present.

Angiopoietin-2 is an antagonist of Ang-1, acting through the Tie-2 receptor and disrupting pericyte-endothelial cell interactions. In the presence of VEGF-A, Ang-2 facilitates vessel sprouting while in its absence, regression of vessel sprouts occurs (Maisonpierre et al, 1997). However, in active tumour angiogenesis, a large proportion of the blood vessels lack pericytes and can be selectively ablated by withdrawal of VEGF-A alone (Benjamin et al, 1999). In our series, survival did not differ significantly where hybridisation for both VEGF-A and Ang-2 was seen and this may reflect a high proportion of immature tumour vessels lacking pericyte coverage. Angiopoietin-2 may also alter the response of destabilised endothelial cells to cytokines, thus modulating angiogenesis (Laurén et al, 1998).

\section{REFERENCES}

Abu-Jawdeh GM, Faix JD, Niloff J, Tognazzi K, Manseau E, Dvorak HF, Brown LF (1996) Strong expression of vascular permeability factor (vascular endothelial growth factor) and its receptors in ovarian borderline and malignant neoplasms. Lab Invest 74: 1105-1115

Abulafia O, Triest WE, Sherer DM, Hansen CC, Ghezzi F (1995) Angiogenesis in endometrial hyperplasia and stage I endometrial carcinoma. Obstet Gynecol 86: 479-485

Achen MG, Jeltsch M, Kukk E, Makinen T, Vitali A, Wilks AF, Alitalo K, Stacker SA (1998) Vascular endothelial growth factor D (VEGF-D) is a ligand for the tyrosine kinases VEGF receptor 2 (Flk1) and VEGF receptor 3 (Flt4). Proc Natl Acad Sci USA 95: 548-553

Benjamin LE, Golijanin D, Itin A, Pode D, Keshet E (1999) Selective ablation of immature blood vessels in established human tumors follows vascular endothelial growth factor withdrawal. J Clin Invest 103: 159- 165

Boocock CA, Charnock-Jones DS, Sharkey AM, McLaren J, Barker PJ, Wright KA, Twentyman PR, Smith SK (1995) Expression of vascular endothelial growth factor and its receptors flt and KDR in ovarian carcinoma. J Natl Cancer Inst 87: 506-516

Charnock-Jones DS, Sharkey AM, Rajput-Williams J, Burch D, Schofield JP, Fountain SA, Boocock CA, Smith SK (1993) Identification and localization of alternately spliced mRNAs for vascular endothelial growth factor in human uterus and estrogen regulation in endometrial carcinoma cell lines. Biol Reprod 48: $1120-1128$

Chomczynski P, Sacchi N (1987) Single-step method of RNA isolation by acid guanidinium thiocyanate-phenol-chloroform extraction. Anal Biochem 162: 156-159

Clark DE, Smith SK, Sharkey AM, Sowter HM, Charnock-Jones DS (1996) Hepatocyte growth factor/scatter factor and its receptor c-met: localisation and expression in the human placenta throughout pregnancy. J Endocrinol 151: 459-467

Davis S, Aldrich TH, Jones PF, Acheson A, Compton DL, Jain V, Ryan TE, Bruno J, Radziejewski C, Maisonpierre PC, Yancopoulos GD (1996) Isolation of angiopoietin-1, a ligand for the TIE2 receptor, by secretiontrap expression cloning. Cell 87: $1161-1169$

Doldi N, Bassan M, Gulisano M, Broccoli V, Boncinelli E, Ferrari A (1996) Vascular endothelial growth factor messenger ribonucleic acid expression in human ovarian and endometrial cancer. Gynecol Endocrinol 10: $375-382$

Ferrara N, Carver-Moore K, Chen H, Dowd M, Lu L, O'Shea KS, PowellBraxton L, Hillan KJ, Moore MW (1996) Heterozygous embryonic lethality induced by targeted inactivation of the VEGF gene. Nature 380: $439-442$

Fine BA, Valente PT, Feinstein GI, Dey T (2000) VEGF, flt-1, and KDR/flk-1 as prognostic indicators in endometrial carcinoma. Gynecol Oncol 76: $33-39$

Folkman J (1990) What is the evidence that tumors are angiogenesis dependent? J Natl Cancer Inst 82: 4-6
We have shown that gene transcripts for the related growth factors, VEGF-A and VEGF-B, are differentially expressed in benign postmenopausal endometrium and endometrioid endometrial cancer. The reduced expression of VEGF-B in endometrial cancers compared with benign endometrium suggests that VEGF-B may play a role in maintaining normal cellular interactions in endometrium and that loss of expression could contribute to endometrial tumorigenesis.

\section{ACKNOWLEDGEMENTS}

This work was supported by a MRC Clinical Training Fellowship, Award number G84/5733; an MRC Programme Grant, Grant number G9623012 and an MRC Cooperative Group Grant number G9722567. We are grateful to Mr Robin Crawford, Mr John Latimer and Dr Robin Moseley, Addenbrookes Hospital, Cambridge, for assistance with tissue collection. We also acknowledge Dr Mark Arends, Department of Pathology, University of Cambridge, for histopathological assessment and Dr Heidi Sowter for technical advice and support.
Fong GH, Rossant J, Gertsenstein M, Breitman ML (1995) Role of the Flt-1 receptor tyrosine kinase in regulating the assembly of vascular endothelium. Nature 376: 66-70

Fujimoto J, Ichigo S, Hirose R, Sakaguchi H, Tamaya T (1998) Expressions of vascular endothelial growth factor (VEGF) and its mRNA in uterine endometrial cancers. Cancer Lett 134: 15-22

Gabrilovich DI, Chen HL, Girgis KR, Cunningham HT, Meny GM, Nadaf S, Kavanaugh D, Carbone DP (1996) Production of vascular endothelial growth factor by human tumors inhibits the functional maturation of dendritic cells. Nat Med 2: 1096-1103

Goede V, Schmidt T, Kimmina S, Kozian D, Augustin HG (1998) Analysis of blood vessel maturation processes during cyclic ovarian angiogenesis. Lab Invest 78: $1385-1394$

Guidi AJ, Abu-Jawdeh G, Tognazzi K, Dvorak HF, Brown LF (1996) Expression of vascular permeability factor (vascular endothelial growth factor) and its receptors in endometrial carcinoma. Cancer 78: $454-460$

Hanahan D (1997) Signaling vascular morphogenesis and maintenance. Science 277: $48-50$

Hirai M, Nakagawara A, Oosaki T, Hayashi Y, Hirono M, Yoshihara T (2001) Expression of vascular endothelial growth factors (VEGF-A/ VEGF-1 and VEGF-C/VEGF-2) in postmenopausal uterine endometrial carcinoma. Gynecol Oncol 80: $181-188$

Holash J, Maisonpierre PC, Compton D, Boland P, Alexander CR, Zagzag D, Yancopoulos GD, Wiegand SJ (1999) Vessel cooption, regression, and growth in tumors mediated by angiopoietins and VEGF. Science 284: $1994-1998$

Houck KA, Ferrara N, Winer J, Cachianes G, Li B, Leung DW (1991) The vascular endothelial growth factor family: identification of a fourth molecular species and characterization of alternative splicing of RNA. Mol Endocrinol 5: 1806-1814

Joukov V, Pajusola K, Kaipainen A, Chilov D, Lahtinen I, Kukk E, Saksela O, Kalkkinen N, Alitalo K (1996) A novel vascular endothelial growth factor, VEGF-C, is a ligand for the Flt4 (VEGFR-3) and KDR (VEGFR-2) receptor tyrosine kinases. EMBO J 15: 1751

Kaku T, Kamura T, Kinukawa N, Kobayashi H, Sakai K, Tsuruchi N, Saito T, Kawauchi S, Tsuneyoshi M, Nakano H (1997) Angiogenesis in endometrial carcinoma. Cancer 80: $741-747$

Lauren J, Gunji Y, Alitalo K (1998) Is angiopoietin-2 necessary for the initiation of tumor angiogenesis? Am J Pathol 153: 1333-1339

Levy AP, Levy NS, Goldberg MA (1996) Post-transcriptional regulation of vascular endothelial growth factor by hypoxia. J Biol Chem 271: 2746 2753

Li XF, Charnock-Jones DS, Zhang E, Hiby S, Malik S, Day K, Licence D, Bowen JM, Gardner L, King A, Loke YW, Smith SK (2001) Angiogenic growth factor messenger ribonucleic acids in uterine natural killer cells. J Clin Endocrinol Metab 86: 1823 - 1834 
Maisonpierre PC, Suri C, Jones PF, Bartunkova S, Wiegand SJ, Radziejewski C, Compton D, McClain J, Aldrich TH, Papadopoulos N, Daly TJ, Davis S, Sato TN, Yancopoulos GD (1997) Angiopoietin-2, a natural antagonist for Tie2 that disrupts in vivo angiogenesis. Science 277: 55 - 60

Millauer B, Shawver LK, Plate KH, Risau W, Ullrich A (1994) Glioblastoma growth inhibited in vivo by a dominant-negative Flk-1 mutant. Nature 367: $576-579$

Ohta Y, Shridhar V, Bright RK, Kalemkerian GP, Du W, Carbone M, Watanabe Y, Pass HI (1999) VEGF and VEGF type C play an important role in angiogenesis and lymphangiogenesis in human malignant mesothelioma tumours. Br J Cancer 81: 54-61

Olofsson B, Korpelainen E, Pepper MS, Mandriota SJ, Aase K, Kumar V, Gunji Y, Jeltsch MM, Shibuya M, Alitalo K, Eriksson U (1998) Vascular endothelial growth factor B (VEGF-B) binds to VEGF receptor-1 and regulates plasminogen activator activity in endothelial cells. Proc Natl Acad Sci USA 95: 11709-11714

Olofsson B, Pajusola K, Kaipainen A, von Euler G, Joukov V, Saksela O, Orpana A, Pettersson RF, Alitalo K, Eriksson U (1996a) Vascular endothelial growth factor B, a novel growth factor for endothelial cells. Proc Natl Acad Sci USA 93: 2576-2581

Olofsson B, Pajusola K, von Euler G, Chilov D, Alitalo K, Eriksson U (1996b) Genomic organization of the mouse and human genes for vascular endothelial growth factor B (VEGF-B) and characterization of a second splice isoform. J Biol Chem 271: 19310-19317

Olson TA, Mohanraj D, Carson LF, Ramakrishnan S (1994) Vascular permeability factor gene expression in normal and neoplastic human ovaries. Cancer Res 54: 276-280

Olson TA, Mohanraj D, Carson LF, Ramakrishnan S (1996) In vivo neutralization of vascular endothelial growth factor (VEGF)/vascular permeability factor (VPF) inhibits ovarian carcinoma-associated ascites formation and tumor growth. Int J Oncol 8: 505-511

Oyama T, Ran S, Ishida T, Nadaf S, Kerr L, Carbone DP, Gabrilovich DI (1998) Vascular endothelial growth factor affects dendritic cell maturation through the inhibition of nuclear factor-kappa B activation in hemopoietic progenitor cells. J Immunol 160: 1224-1232
Salvesen HB, Akslen LA (1999) Significance of tumour-associated macrophages, vascular endothelial growth factor and thrombospondin1 expression for tumour angiogenesis and prognosis in endometrial carcinomas. Int J Cancer 84: 538-543

Shalaby F, Rossant J, Yamaguchi TP, Gertsenstein M, Wu XF, Breitman ML Schuh AC (1995) Failure of blood-island formation and vasculogenesis in Flk-1-deficient mice. Nature 376: 62-66

Silins G, Grimmond S, Egerton M, Hayward N (1997) Analysis of the promoter region of the human VEGF-related factor gene. Biochem Biophys Res Commun 230: 413-418

Sowter HM, Corps AN, Evans AL, Clark DE, Charnock-Jones DS, Smith SK (1997) Expression and localization of the vascular endothelial growth factor family in ovarian epithelial tumors. Lab Invest 77: 607-614

Thurston G, Suri C, Smith K, McClain J, Sato TN, Yancopoulos GD, McDonald DM (1999) Leakage-resistant blood vessels in mice transgenically overexpressing angiopoietin-1. Science 286: $2511-2514$

Tischer E, Mitchell R, Hartman T, Silva M, Gospodarowicz D, Fiddes JC, Abraham JA (1991) The human gene for vascular endothelial growth factor. Multiple protein forms are encoded through alternative exon splicing. J Biol Chem 266: 11947-11954

Waltenberger J, Claesson-Welsh L, Siegbahn A, Shibuya M, Heldin CH (1994) Different signal transduction properties of KDR and Flt1, two receptors for vascular endothelial growth factor. J Biol Chem 269: 26988 26995

White JD, Hewett PW, Kosuge D, McCulloch T, Enholm BC, Carmichael J, Murray JC (2002) Vascular endothelial growth factor-D expression is an independent prognostic marker for survival in colorectal carcinoma. Cancer Res 62: 1669-1675

Yokoyama Y, Charnock-Jones DS, Licence D, Yanaihara A, Hastings JM, Holland CM, Emoto M, Sakamoto T, Maruyama, H, Sato S, Mizunuma H, Smith SK (2003) Expression of vascular endothelial growth factor (VEGF)-D and its receptor, VEGF Receptor 3, as a prognostic indicator in endometrial carcinoma. Clin Cancer Res 9: $1361-1369$ 